\title{
Analisis Penerapan Sistem Informasi Manajemen pada Kegiatan Logistik di Indonesia
}

\author{
Syehan Sasmito Muslim ${ }^{\mathrm{a}}$, Nurcahyo Ageng Wibowo ${ }^{\mathrm{b}}$, Faris Nofandi ${ }^{\mathrm{c}^{*}}$ \\ a,b,c Jurusan Transportasi Laut (Politeknik Pelayaran Surabaya) \\ aEmail: hgo0371@gmail.com \\ bEmail: cahyo3090@gmail.com \\ c*Email: faris.nofandi@poltekpel-sby.ac.id
}

\begin{abstract}
ABSTRAK
Sistem informasi merupakan perangkat yang umumnya digunakan pada suatu organisasi ataupun perusahaan dalam memanajemen data ataupun informasi. Kelebihan dari sistem informasi ini salah satunya adalah dalam perihal pencarian informasi data yang diperlukan oleh industri. Kegiatan logistik memerlukan suatu sistem informasi yang dapat merepresentasikan keadaan nyata yang memuat keseluruhan aktivitas guna memperlancar aktivitas logistik serta pengambilan kebijakan-kebijakan logistik secara cepat dan akurat. Oleh sebab itu perlu adanya sistem data terintegrasi untuk mendukung seluruh aktivitas logistik. Tujuan Penelitian ini adalah untuk menganalisis penerapan sistem data manajemen dalam pengelolaan logistik pada suatu industri. Manfaatnya adalah untuk mempermudah dalam mengatasi masalah keterlambatan dalam pengiriman data informasi. Adapun metode yang digunakan dalam penelitian ini menggunakan jenis penelitian deskriptif kualitatif.. Hasil pencarian informasi tersebut pada akhirnya akan disimpan dan kemudian dijadikan database pada industri, sehingga ketika industri memerlukan pencarian data bisa lebih mudah dilakukan secara cepat dan akurat.
\end{abstract}

Kata Kunci : sistem informasi manajemen, logistik, cepat dan akurat

\begin{abstract}
Information systems are devices that are generally used in an organization or company in managing data or information. One of the advantages of this information system is in the search for data information needed by the industry. Logistics activities require an information system that can represent a real situation that contains all activities to expedite logistics activities as well as making logistics policies quickly and accurately. Therefore it is necessary to have an integrated data system to support all logistical activities. The purpose of this study was to analyze the application of management data systems in logistics management. The benefit is to make it easier to solve the problem of delays in sending information data. The method used in this research is descriptive qualitative research. The results of this information search will eventually be stored and then used as a database in the industry so that when the industry requires data retrieval it can be easier to do it quickly and accurately.
\end{abstract}

Keywords: management information systems, logistics, fast and accurate

\section{PENDAHULUAN}

Dalam suatu perusahaan, bagian logistik mempunyai peran yang penting, hal ini dikarenakan pada bagian logistik berkaitan dengan penanganan material dan barang lainnya sebagai penunjang pelaksanaan kegiatan operasional suatu perusahaan. Guna membantu kegiatan logistik tersebut, diperlukan suatu sistem informasi yang dapat merepresentasikan keadaan nyata di bagian logistik yang memuat keseluruhan aktivitas logistik guna memperlancar aktivitas logistik serta pengambilan kebijakan-kebijakan 
logistik secara cepat dan akurat (Villela, 2013). Hal ini penting mengingat ketatnya persaingan dengan para kompetitor.

Sebuah perusahaan baik dalam skala kecil maupun skala besar, baik yang berkaitan dengan penjualan barang atau jasa tentu memperhitungkan efisiensi serta keefektifan (Indrayani, 2012). Penyebabnya sederhana, karena efisiensi serta keefektifan pasti akan membawa keuntungan yang besar untuk suatu industri. Sebuah perusahaan harus bisa mengupayakan barang atau jasa yang dijual ataupun ditawarkan mampu sampai di waktu yang tepat, di tempat yang sesuai, serta mutu dan kualitas barang atau jasa tersebut tidak cacat serta sesuai dengan permintaan. Perihal tersebut dalam rangka upaya menjaga keberlangsungan perusahaan itu sendiri. Sebuah logika yang sederhana, apabila pelanggan puas dengan pelayanan yang diberikan pasti pelanggan tersebut akan kembali lagi.

Logistik berkaitan erat dengan pengaturan barang atau jasa untuk mendukung keberhasilan perusahaan dalam melakukan efisiensi dan keefektifan dalam menjual produk perusahaan tersebut baik barang atau jasa (Afifah \& Setyantoro, 2021). Pengaturan barang atau jasa yang dimaksud dalam hal ini yaitu barang atau jasa yang digunakan sebagai operasional industri. Untuk hal tersebut diperlukan sebuah manajemen logistik yang baik dan benar. Jika logistik diatur ataupun dikelola (manajemen) dengan baik, tentu akan tercapai tujuan efisiensi dan keefektifan yang akan membawa keuntungan besar untuk perusahaan ataupun minimum menghindari terjadinya kerugian. Perihal tersebut mendasari penelitian ini, dalam menuliskan sesuatu tentang manajemen logistik yang baik dan benar demi tercapainya tujuan yang disebutkan dengan mengintegrasikan suatu sistem data yang bisa mendukung dan mempermudah aktivitas dalam suatu manajemen logistik.

\section{METODE}

Jenis penelitian ini adalah penelitian deskriptif kualitatif. Penelitian yang mempunyai tujuan untuk menarasikan suatu fenomena, peristiwa, atau hal yang didapat lewat data tulisan, setelah itu disusun ke dalam wujud tulisan sehingga bisa dibaca serta disimpulkan (Subandi, 2011). Dengan demikian, penelitian ini memiliki kebutuhan akan sumber informasi yang berasal dari permasalahan lapangan yang diteliti. Sumber data berarti suatu bentuk subjek darimana asal datanya diperoleh (Arikunto, 2006). Teknik pengumpulan data dalam penelitian ini merupakan melalui penyelidikan pada sumbersumber tulisan ataupun biasanya pada metode penelitian disebut dengan library research (penelitian pustaka), pencatatan, ataupun dengan metode pengamatan. Instrumen dalam penelitian ini merupakan peneliti itu sendiri. Langkah pengumpulan informasi penelitian:

1. Membaca karya sastra

2. Memahami teori

3. Menguasai metode

4. Mencari dan menemukan data

5. Menganalisis informasi yang ditemui secara mendalam

6. Melaksanakan revisi secara menyeluruh

7. Membuat simpulan penelitian.

\section{HASIL DAN PEMBAHASAN}

Inventarisasi ialah suatu aktivitas melaksanakan perhitungan jumlah sisa barang yang ada saat ini dibandingkan dengan administrasi pembukuan dengan melakukan tutup buku (closing) tiap bulan, triwulan, serta tahunan (Wati et al., 2020). Dalam melakukan inventarisasi, tercantum aset yang digunakan baik yang bergerak ataupun yang tidak bergerak. Tidak hanya perihal tersebut, jumlah fisik wajib sama dengan catatan (SAP/Sederhana As Possible).

Peramalan permintaan ialah suatu upaya agar tidak terjalin kelebihan 
penyimpanan barang ataupun penyediaan jasa sehingga harus diukur ataupun ditentukan terlebih dulu sejauh mana permintaan yang ada dalam membuat prakiraan terhadap permintaan barang atau jasa tersebut (Auliasari et al., 2020).

Pemilihan vendor/rekanan dengan diadakannya seleksi vendor/rekanan yang dimaksudkan untuk memelihara serta memperoleh vendor yang valid serta sudah terbukti performanya sehingga pembelian cocok dengan persyaratan yang diinginkan (Andriyanto, Achmad dan Wishnuartini, 2019). Prosedur ini berlaku untuk vendor lama maupun baru dalam pengadaan barang serta ataupun jasa. Ada sebagian form untuk melaksanakan seleksi vendor/rekanan ialah:

1. Evaluasi calon vendor baru/lama

2. Berita acara penilaian vendor

3. Daftar vendor terseleksi

4. Vendor blacklist.

Purchasing dalam pengadaan barang serta ataupun jasa strategis dengan metode tender maupun pengadaan langsung, tata cara penilaian yang digunakan adalah analisis "QCDS". QCDS merupakan $Q$ (quality), $C$ (cost), $D$ (delivery), $S$ (source). Pengadaan barang (purchasing) bisa dicoba dengan metode:

1. Membeli (buying);

2. Sewa (hire), tukar menukar, sewa beli (leasing) serta membeli dengan uji lapangan (buy or return).

Penerapan pengadaan dicoba dengan metode satu pintu (one gate policy) oleh unit fungsional logistik.

Pengelolaan barang (material handling) diperlukan tahapan adminstrasi yang baik. Adapun tahapan administrasi barang tersebut yaitu:

1. Penerimaan barang di gudang dilaksanakan berdasarkan Dokumen Pengantar Barang (DPB) yang bersangkutan;

2. Persiapan penerimaan barang melalui tahapan yaitu; a. Pembentukan panitia pemeriksa dan pengujian barang serta menyiapkan tempat dan peralatan yang diperlukan

b. Penyerahan barang oleh vendor/rekanan

c. Penerimaan sementara meliputi penandatanganan Dokumen Pengantar Barang ( $D P B)$

d. Memeriksa dan/atau menguji barang yang diterima

e. Serah terima atau pembuatan dan penandatanganan berita acara penerimaan barang.

3. Pada tahap penerimaan sementara dan pengecekan status kepemilikan barang, belum dialihkan dari vendor ke pihak pertama;

4. Hasil pemeriksaan muatan harus dicantumkan dalam formulir laporan pemeriksaan;

5. Setelah dilakukan penandatanganan Berita acara penerimaan, maka status kepemilikan barang berpindah kepada pihak pertama.

Penerimaan material adalah semua kegiatan yang berkaitan dengan kepabeanan, pemeriksaan dan penelitian material impor dan dalam negeri yang berkaitan dengan operasional perusahaan, penyelesaian administrasi dan pengiriman material ke fungsi terkait. Dapat dilihat pada bagan berikut:

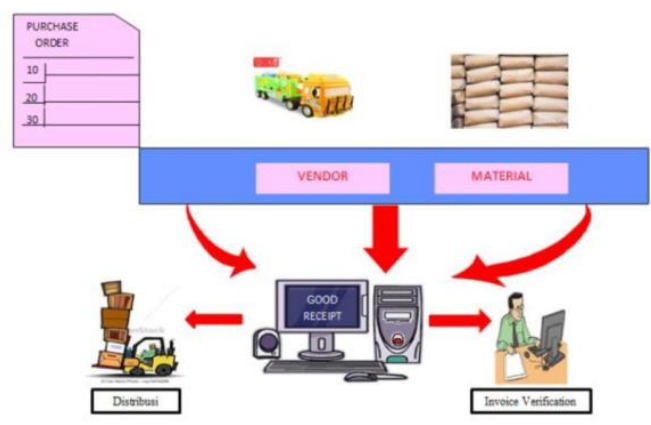

Gambar 1. Bagan Penerimaan Material.

Tanggung jawab untuk penerimaan material tergantung pada persyaratan pengiriman yang tercantum dalam Purchase Order (PO) dan persyaratan pengiriman lainnya. Pemeriksaan fisik meliputi:

1. Jumlah/kuantitas

2. Spesifikasi material 
3. Kualitas dan syarat lainnya.

Pemeriksaan dilakukan oleh fungsi pengadaan sendiri atau bersama dengan fungsi terkait/jasa inspeksi independen.

Setelah menerima material, maka material tersebut perlu disimpan dan dilakukan perawatan. Dalam penyimpanan atau penempatan gudang material harus memperhatikan sifat dan karakteristik barang, selain itu setiap material yang disimpan harus disertai dengan tanda pengenal nomor material (Hidayati \& Purnomo, 2013). Penyimpanan dan penempatan stok material dilakukan dengan mengacu pada sistem urutan nomor material. Sedangkan untuk perawatan material harus memiliki fungsi penyimpanan untuk menjaga dan memelihara material yang disimpan agar selalu dalam kondisi baik dan siap pakai. Pemilihan metode material handling dipengaruhi oleh jenis/karakteristik material, area penyimpanan, kondisi iklim, dan biaya.

Penggudangan

(warehouse) terdapat beberapa hal yang harus diperhatikan dalam fasilitas penyimpanan yaitu:

1. Pembangunan gudang dan fasilitas penunjang;

2. Perlengkapan/fasilitas meliputi:
a. Metode pengangkatan
pemindahan;

b. pengepakan;

c. pemeriksaan;

d. alat/fasilitas perawatan;

e. alat/fasilitas penyimpanan;

f. fasilitas keamanan dan keselamatan.

The objectives of warehouse management memiliki beberapa aturan dalam mengelola atau mengelola gudang, yaitu:

1. Penyelesaian order semaksimal mungkin dengan kuantitas dan waktu yang benar;

2. Meminimalkan biaya operasional gudang;

3. Maksimalkan perputaran persediaan (meminimalkan waktu tinggal bahan di gudang);
4. Meminimalkan waktu layanan pesanan dan kesalahan pemrosesan pesanan;

5. Menjaga kualitas, nilai, dan keamanan bahan yang disimpan di gudang. Selain itu aktivitas pengelolaan material stok secara fisik dan nilainya meliputi:

a. Penerimaan;

b. Penyimpanan;

c. Perawatan;

d. Pengeluaran;

e. Pencatatan;

f. Pemeriksaan fisik.

Ada dua tugas penyimpanan

(warehousing) yaitu:

1. Mengirimkan produk secara efisien ke pengguna tanpa kesalahan;

2. Tempatkan produk yang tepat di tempat yang tepat pada waktu yang tepat.

Adapun diadakannya warehousing memiliki beberapa tujuan yaitu:

1. Meningkatkan fungsi service order (order picking operations);

2. Meningkatkan produktivitas;

3. Meningkatkan penggunaan ruang (use space);

4. Layanan nilai tambah (value added services).

Tugas serta fungsi dari warehousing dapat dilihat pada bagan berikut:

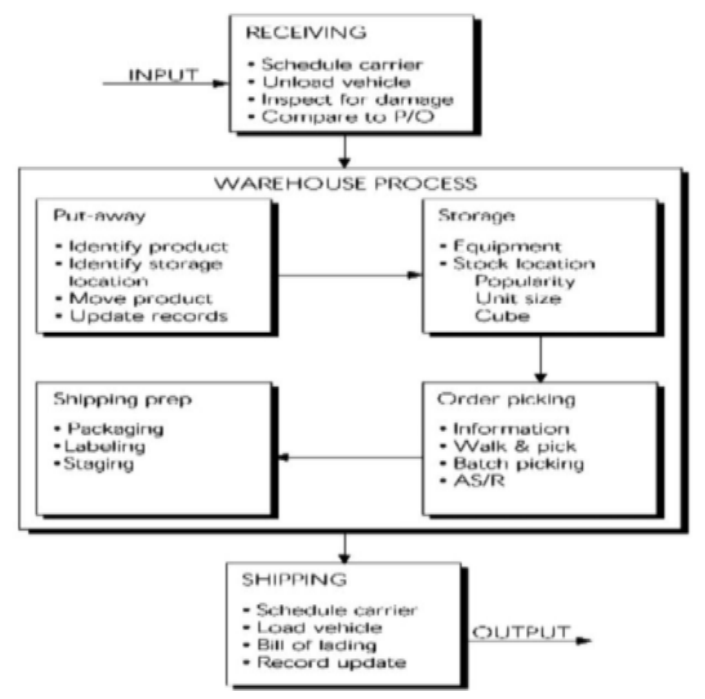

Gambar 2. Bagan fungsi warehousing.

Inventory Control Inventory adalah persediaan barang (Kiran, 2017). Manajemen inventaris berfokus pada 
perencanaan dan pengendalian produk jadi, bahan mentah, suku cadang yang dibeli, dan pekerjaan yang sedang berjalan. Berikut bagan dari penjelasan tentang inventory yaitu:

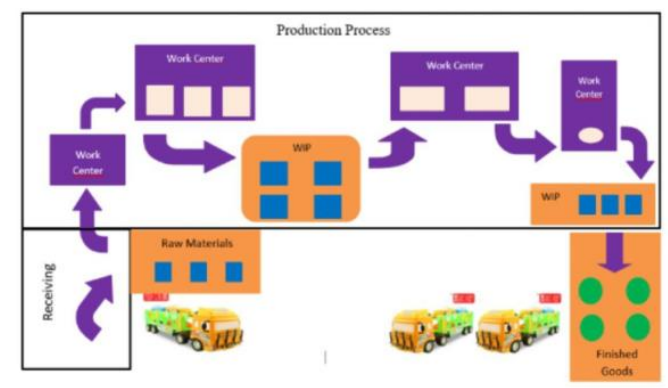

Gambar 3. Bagan inventory

Ada beberapa alasan perlunya inventarisasi dalam manajemen logistik. Alasan tersebut adalah:

1. Menjaga independensi/kemandirian operasi;

2. Memenuhi demand/permintaan yang bervariasi;

3. Jadwal operasi yang fleksibel;

4. Pengaman dari variabilitas pengiriman rawmaterials;

5. Mengambil bonus/keuntungan diskon kuantitas;

6. Menjaga dampak inflasi dan kenaikan harga.

Kaizen merupakan gabungan dua kata, yaitu kai dan zen (Tetteh, 2012). Kata kai yang berarti mengubah sementara kata zen yang berarti lebih baik. Kaizen dibaca kaiseng. Secara sederhana, definisi kaizen yaitu usaha perbaikan berkelanjutan untuk menjadi lebih baik dari kondisi sekarang, Kaizen dapat diartikan suatu sistem perusahaan yang komprehensif yang dilakukan dalam rangka perbaikan secara terus menerus (continuous improvement) untuk mencapai kondisi yang lebih baik dari hari ini.

Pilar utama dari kaizen adalah Quality Control Circle, SS (Suggestion system), 5S (Seiri seiton seiso seiketsu, shitsuke), dan 3M (Muda, Mura, Muri). Muda yang artinya eliminasi waste, sementara Mura artinya tidak beraturan, tidak konsisten, terakhir yaitu muri yang artinya tidak boleh berlebihan. Sementara 5S sendiri yaitu : 1) Seiri =
Sort $=$ Ringkas 2) Seiton $=$ Set in Order = Rapi 3) Seiso = Shine $=$ Resik 4) Seiketsu $=$ Standardize $=$ Rawat 5) Shitsuke $=$ Sustain $=$ Rajin, Sasaran utama kaizen menghilangkan pemborosan (waste) yang tidak memberikan nilai tambah (value added) produk atau jasa dari perspektif konsumen dan juga mengurangi biaya sehingga keuntungan meningkat. Berikut ini merupakan 3 prinsip dari kaizen, yaitu:

1. Hasilnya tidak bisa diperbaiki, hanya pada proses yang bisa diperbaiki;

2. Fokus pada total sistem, jangan menggunakan metode fragmented;

3. Lihatlah semua permasalahan dengan cara pandang untuk tidak mencari siapa yang salah.

Sistem Informasi yang terintegrasi dalam manajemen logistik untuk memudahkan, manajemen logistik yang tepat membutuhkan sistem informasi yang terintegrasi ke dalam sistem manajemen ini, seperti yang telah dijelaskan sebelumnya. Sistem informasi sangat penting untuk kemudahan penggunaan. Oleh karena itu, terdapat sistem informasi yang dapat mendukung pengelolaan logistik.

Fungsi, tugas, dan tujuan dari manajemen logistik ini yaitu membuat kerangka kerja pelaksanaan manajemen logistik yang lebih efektif dan efisien berdasarkan fungsi, tugas, dan tujuan manajemen logistik yang terdiri dari tujuan jangka pendek, menengah, dan panjang perusahaan. Ini juga dapat digunakan sebagai bahan referensi dasar bagi operator dan manajer dalam menjalankan aktivitas untuk mencapai pengelolaan gudang yang lancar, aman, dan efisien. Pada saat yang sama, tugas manajemen logistik adalah menciptakan sistem atau proses yang sepenuhnya terencana atau konseptual dari awal hingga akhir. Tujuan dari manajemen logistik adalah sebagai berikut:

1. Untuk memberikan kepastian serta menyeragamkan prosedur standar 
untuk menerapkan manajemen pengelolaan pergudangan;

2. Untuk mempermudah dan mempercepat pemeriksaan, penerimaan, dan pengeluaran barang untuk mendukung kegiatan perusahaan;

3. Untuk meningkatkan pengendalian persediaan melalui manajemen pengelolaan pergudangan secara optimal baik dari segi pemanfaatan sarana maupun sistem pendukungnya;

4. Untuk mempertahankan fungsi dan menjaga kondisi barang yang disimpan serta kondisi fisik gudang agar tetap terawat dan siap pakai setiap waktu;

5. Untuk mempermudah dalam penyajian data dan informasi yang cepat dan akurat dalam keperluan administrasi perusahaan.

\section{SIMPULAN}

Berdasarkan hasil makalah penelitian di atas maka dapat ditarik kesimpulan bahwa sistem informasi logistik dan manajemen pergudangan ini dapat digunakan untuk menghasilkan laporan dengan informasi seperti stok barang, pembelian, dan peramalan kebutuhan permintaan di masa mendatang, pelaporan, dan nilai barang dan aset untuk membantu manajemen/manajer dalam menganalisis dan membuat keputusan yang terkait dengan aktivitas layanan logistik perusahaan.

Data dari sistem ini dapat saling terhubung dengan data-data yang lain sehingga mudah digunakan untuk mendukung kegiatan bisnis di dalam perusahaan mulai dari penyimpanan, perhitungan, pengelolaan, dan pembuatan laporan dengan mudah.

Apabila dibandingkan dengan sistem yang lama/konvensional, pada sistem ini membuat waktu pelaporan lebih singkat, lebih mudah, cepat, dan akurat.
V. DAFTAR PUSTAKA

Afifah, V., \& Setyantoro, D. (2021).

Rancangan Sistem Pemilihan dan

Penetapan Harga dalam Proses

Pengadaan Barang dan Jasa

Logistik Berbasis Web. Jurnal

IKRA-ITH INFORMATIKA, 5(2), 108-117.

Andriyanto, Achmad dan Wishnuartini, N. A. (2019). Evaluasi Kinerja Supplier Connector Di PT Len Industri (Persero) Untuk Menentukan Peringkat Supplier Connector Terbaik Dengan ISSN: 2086-8561. Jurnal Logistik Bisnis, Vol. 09, No.2, 09(2), 16-25.

Arikunto, S. (2006). Prosedur penelitian: suatu pendekatan praktik. Rineka Cipta.

Auliasari, K., Kertaningtyas, M., \& Kriswantono, M. (2020).

Penerapan Metode Peramalan untuk Identifikasi Permintaan Konsumen. INFORMAL: Informatics Journal, 4(3), 121. https://doi.org/10.19184/isj.v4i3.14 615

Hidayati, M. A., \& Purnomo, H. (2013). Perancangan Tata Letak Gudang Produk Jadi Menggunakan Association Rule Mining Di PT. Supratik Suryamas Yogyakarta. Journal of Chemical Information and Modeling, 53(9), 1689-1699.

Indrayani, H. (2012). Penerapan

Teknologi Informasi Dalam Peningkatan Efektivitas, Efisiensi dan Produktivitas Perusahaan. Jurnal El-Riyasah, 68-70.

Kiran, D. R. (2017). Terminology Used in Japanese Management Practices. Total Quality Management, 2002, 499-511.

https://doi.org/10.1016/b978-0-12811035-5.00036-2

Subandi. (2011). Deskripsi Kualitatif Sebagai Satu Metode Dalam Penelitian Pertunjukan. Harmonia: Journal of Arts Research and Education, 11(2), 173-179. https://doi.org/10.15294/harmonia. v11i2.2210 
Tetteh, H. A. (2012). Kaizen: A Process

Improvement Model for the

Business of Health Care and

Perioperative Nursing

Professionals. AORN Journal,

95(1), 104-108.

https://doi.org/https://doi.org/10.10

16/j.aorn.2011.11.001

Villela, Lucia Maria Aversa. (2013).

Manajemen Logistik. In Journal of

Chemical Information and

Modeling (Vol. 53, Issue 9).

Wati, A. S., Maria, E., \& Cahyono, A.

D. (2020). Otomatisasi Sistem

Inventarisasi Barang di Sekolah:

Studi pada SD Negeri Sidorejo Lor

06, Salatiga. Aiti, 17(1), 56-71.

https://doi.org/10.24246/aiti.v17i1.

56-71 